\title{
АВТОМАТИЗАЦІЯ СИНТЕЗУ ПРОГРАМНОГО КОДУ ВУЗЛА МЕРЕЖІ ПЕТРІ ДЛЯ МОВИ МОДЕЛЮВАННЯ РОSES++
}

\begin{abstract}
Аннотация: Проведений огляд систем моделювання мережами Петрі, показані переваги використання в якості зовнішнього середовища моделювання CASE-пакету системи POSES++. Визначена формальна модель вузла, задана контекстно-вільна граматика для синтезу програмного коду вузлу. Розглянуто приклад застосування правил граматики.
\end{abstract}

Ключові слова: мережі Петрі, CASE-пакет, POSES++, правила граматики.

\section{Вступ}

Теорія мереж Петрі є добре відомим засобом формального опису, основне призначення якого - моделювання та аналіз роботи з паралельними та асінхроними системами. У мережі Петрі вузол характеризуе деякий стан системи, а перехід - дію, що відбуваеться у системі. Система, перебуваючи в певному стані, може породжувати дії; виконання дій переводить систему з одного стану в інший.

Наразі існуе багато систем, які дозволяють проводити моделювання з використанням мереж Петрі. Проте більшість з систем являють собою деякий спеціалізований інструментарій, для вільного володіння яким необхідно бути не лише фахівцем із мереж Петрі, а й фахівцем відповідного програмного продукту.

Альтеративним шляхом е використання так званих CASE- засобів, які дозволяють користувачеві будувати модель за допомогою візуального інтерфейсу та здійснювати параметричне налаштування побудованої моделі, після чого побудова програмного коду здійснюеться за деякою формалізованою схемою [1]. У роботі [2] розглянуті особливості взаємодії CASE- засобу із системою імітаційного моделювання, та обгрунтована доцільність використання системи імітаційного моделювання як окремого застосування. При цьому на вхід застосування подається файл з програмним кодом імітаційної моделі, а на виході отримуеться файл із результатами проведення експерименту над моделлю.

Проте цей підхід можливий лише у тому випадку, коли система моделювання має відкритий формат зберігання файлів із програмним кодом та результатами експериментів. Характеристика систем моделювання мережами Петрі, згідно із даними [3], наведена у наступній таблиці:

Для інтеграції із CASE-засобом можуть бути використані системи моделювання Maria, PNML FrameWork, POSES++ та SNAKES, так як вони мають відкритий формат збереження моделей та не мають власного графічного інтерфейсу.

(c) Н.В. Богушевська, М.А. Баляниця, 2011 
Характеристика систем моделювання мережами Петрі

\begin{tabular}{|c|c|c|c|c|}
\hline $\begin{array}{l}\text { Назва } \\
\text { системи }\end{array}$ & $\begin{array}{l}\text { Має від- } \\
\text { критий } \\
\text { формат } \\
\text { збері- } \\
\text { гання } \\
\text { даних } \\
\end{array}$ & $\begin{array}{l}\text { Має } \\
\text { візу- } \\
\text { альний } \\
\text { інтер- } \\
\text { фейс }\end{array}$ & Переваги & Недоліки \\
\hline $\begin{array}{l}\text { CPN } \\
\text { Tools }\end{array}$ & + & + & $\begin{array}{l}\text { Зручний } \\
\text { чний інтерфей- } \\
\text { чнйс }\end{array}$ & \begin{tabular}{|lr} 
Формат & збере- \\
ження & моделі \\
базується & на мові \\
ХМL. & Вбудовані \\
засоби & аналізу \\
моделі & недостатні \\
для & вирішення \\
прикладних задач \\
\end{tabular} \\
\hline Geist3D & - & - & \begin{tabular}{|l|} 
Tривимірне \\
представлення \\
моделі, запис \\
відео-результатів \\
моделювання \\
\end{tabular} & $\begin{array}{l}\text { Відсутні можливо- } \\
\text { сті анімації резуль- } \\
\text { татів }\end{array}$ \\
\hline Maria & + & - & $\begin{array}{l}\text { Представлення } \\
\text { моделі здійснено } \\
3 \text { використанням } \\
\text { формальної мо- } \\
\text { ви з можливістю } \\
\text { розширення }\end{array}$ & \\
\hline Petrigen & - & + & $\begin{array}{l}\text { Використання мо- } \\
\text { ви декларативної } \\
\text { мови для пред- } \\
\text { ставлення моделі }\end{array}$ & $\begin{array}{l}\text { Обмежені можли- } \\
\text { вості аналізу моде- } \\
\text { лі }\end{array}$ \\
\hline $\begin{array}{l}\text { PNML } \\
\text { Frame } \\
\text { Work }\end{array}$ & + & & $\begin{array}{l}\text { Сумісність з ба- } \\
\text { гатьма інструмен- } \\
\text { тами візуального } \\
\text { представлення мо- } \\
\text { делей засобами ме- } \\
\text { реж Петрі }\end{array}$ & \\
\hline
\end{tabular}

Найпотужнішою 3 перелічених систем моделювання $е$ система POSES++, яка може застосовуватися для моделювання дискретноподійних систем (логістика, апаратне забезпечення) та реалізована у вигляді кліснт-серверного застосування з можливістю розподілених обчислень.

Роботи $[4,5]$ присвячені питанням розробки фрормальних моделей 


\begin{tabular}{|c|c|c|c|c|}
\hline $\begin{array}{l}\text { Назва } \\
\text { системи }\end{array}$ & $\begin{array}{l}\text { Має від- } \\
\text { критий } \\
\text { формат } \\
\text { збері- } \\
\text { гання } \\
\text { даних }\end{array}$ & \begin{tabular}{|l} 
Має \\
візу- \\
альний \\
інтер- \\
фейс
\end{tabular} & Переваги & Недоліки \\
\hline POSES++ & + & - & $\begin{array}{l}\text { Можливість реалі- } \\
\text { зації розподілених } \\
\text { обчислень. }\end{array}$ & $\begin{array}{ll}\text { Вимагае } \\
\text { мови С }\end{array}$ \\
\hline SNAKES & + & - & 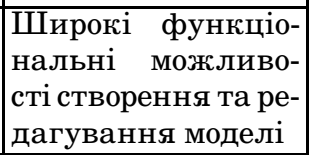 & $\begin{array}{l}\text { Вимагае знання } \\
\text { мови Python }\end{array}$ \\
\hline Snoopy & - & + & $\begin{array}{l}\text { Розвинена система } \\
\text { візуального пред- } \\
\text { ставлення процесу } \\
\text { симуляції моделі }\end{array}$ & $\begin{array}{l}\text { Не підтримуе ко- } \\
\text { льорові мережі Пе- } \\
\text { трі }\end{array}$ \\
\hline StpnPlay & + & + & $\begin{array}{l}\text { Використання за- } \\
\text { собів багато пото- } \\
\text { кового моделюван- } \\
\text { ня }\end{array}$ & $\begin{array}{l}\text { Відсутні можливо- } \\
\text { сті анімації резуль- } \\
\text { татів }\end{array}$ \\
\hline Tina & - & + & \begin{tabular}{|l|} 
Потужні аналіти- \\
чні можливості, \\
можливість збере- \\
ження результатів \\
у різних фооматах
\end{tabular} & \\
\hline TAPAAL & + & + & $\begin{array}{l}\text { Потужні аналі- } \\
\text { тичні можливості } \\
\text { аналізу та верифі- } \\
\text { кації моделей }\end{array}$ & $\begin{array}{l}\text { Не підтримуе ко- } \\
\text { льорові мережі Пе- } \\
\text { трі }\end{array}$ \\
\hline $\begin{array}{l}\text { Visual } \\
\text { Object } \\
\text { Net ++ }\end{array}$ & - & + & $\begin{array}{l}\text { Можливість ство- } \\
\text { рення та аналізу } \\
\text { гібридних моде- } \\
\text { лей (дискретно- } \\
\text { неперервних). } \\
\text { Генерація звітно- } \\
\text { сті по проведених } \\
\text { експериментах }\end{array}$ & \\
\hline
\end{tabular}

основних конструкцій мови POSES++ та правил перетворення формальної моделі типу даних до програмного коду мовою POSES++.

\section{Постановка задачі}

Для розробки правил перетворення вузла мережі Петрі до програмного коду мовою POSES++ необхідно: 
1. визначити алфавіт термінальних символів вузлу $A_{\text {nodes }}$;

2. визначити алфавіт нетермінальних символів вузлу $N_{\text {nodes }}$;

3 . визначити початковий символ $S_{\text {nodes }}$;

4. визначити множину правил виводу $R_{\text {nodes }}$;

5. створити діалогову нотацію відповідно до формальної моделі.

\section{Формальна модель вузла}

\section{Визначення алфавіту термінальних символів}

Формальна модель вузлу мережі Петрі має такий вигляд [1]:

Node $=<$ Name, TokenType, Capacity, AccessMode, Initial $>$,

де Name - найменування вузла, TokenType $\in$ Token - тип даних маркера у вузлі, Capacity - емність вузла, AccessMode $\in$ Access - режим доступу у вузлі, Initial - множина значень, що визначають початкову розмітку вузлу.

Множина Access визначає можливі режими доступу маркерів у вузлі, для мови POSES++ :

Access $=\{$ RAM, FIFO, LIFO, FIFORAM, LIFORAM,PLACE $\}$.

Алфавіт $A_{\text {nodes }}$ представимо у вигляді

$$
A_{\text {nodes }}=A_{\text {nodes }}^{0} \cup A_{\text {nodes }}^{\prime},
$$

де $A_{\text {nodes }}^{0}$ містить термінали, що відповідають операторам мови POSES++, $A_{\text {nodes }}^{\prime}$ - містить термінали “найменування".

Визначимо множину можливих роздільників $A_{d e l}$ та множину типів даних $A_{\text {types }}$ наступним чином:

$A_{\text {types }}=\{$ 'char', 'short', 'int', 'long', 'f loat', 'double', '\$', 'string', 'enum', 'struct' $\}$,

$$
A_{\text {del }}=\{, ;,, \text {, , '\}, ', ', '<', '>', '(', ')' }\} \text {. }
$$

Тоді

$$
A_{\text {nodes }}^{0}=A_{\text {types }} \cup A_{\text {del }} \backslash\{\text { 'enum,',struct,',\{,',','(',')'\} . }
$$

Позначимо через $A_{\text {aсc }}$ алфравіт режимів доступу:

$$
A_{a c c}=\{\text { 'ram', 'f if o', 'lif o', 'f if oram', 'lif oram', 'place' }\},
$$


Визначення алфавіту нетермінальних символів та початкового символу

Множини алфавіту не термінальних символів $N_{\text {nodes }}$ та початкового символу $S_{\text {nodes }}$ матимуть вигляд:

$N_{\text {nodes }}=\{$ Node, Node1, Node2, AccessMode1, AccessMode2, TokenType, LPar, RPar, Coma, Number, Name, Variable, Initial, End\},

$$
S_{\text {nodes }}=\{\text { Node }\} .
$$

\section{Визначення множини правил виводу}

Множина правил виводу $R_{\text {nodes }}$ :

1. $<$ Node $>::=<$ Node $1>\mid<$ Node2 $>$

2. $<$ Node1 $>::=<$ AccessMode $1><$ LPar $><$ TokenType $><$ Coma $>$ $<$ Number $><$ RPar $><$ Name $><$ Initial $>$

3. $<$ Node2 $>::=<$ AccessMode2 $><$ LPar $><$ Number $><$ RPar $><$ Name $><$ Initial $>$

4. $<$ AccessMode1 $>::=$ ram I fifo I lifo I fiforam I liforam $<$

5. $<$ AccessMode2 $>::=$ place

6. $<$ TokenType $>::=$ char I short I int I long | float | double | string | < Variable $>$

7. $<$ LPar $>::=<$

8. $<$ RPar $>::=>$

9. $<$ Coma $>::=$,

10. $<$ Name $>::=$ Name

11. $<$ Number $>::=$ Number

12. $<$ Variable $>::=$ Variable

13. $<$ Initial $>::=<$ LPar $><$ LPar $>$ Number $(<$ Initial $>) \mid<$ End $>$ I card(Number) $<$ Coma $><$ BlackToken $>$

14. $<$ End $>::=$,

15. $<$ BlackToken $>::=\$$

Алгоритм застосування правил 1) - 15) для отримання програмного коду має такий вигляд:

1. Визначення типу вузла. Якщо вузол містить чорні маркери, то застосувати правило 3 , інакше - правило 2 .

2. Поки є нетермінальні символи, застосовувати найменше з правил 4) $-15)$. 


\section{Приклад застосування}

Розглянемо приклад. Нехай формальна модель (1) має вигляд

$$
\text { Node }=<\mathrm{n} 1 \text {, int, } 5 \text {, lif } 0,\{1,2,3\}>\text {. }
$$

Для цього прикладу $A_{n o d e s}^{=}\{\mathrm{n} 1,5,\{1,2,3\}\}$. Покрокове застосування правил $R_{\text {nodes }}$, з урахуванням (4) - $(9)$, матиме наступний вигляд:

Правило 1

$$
<\text { Node }>::=<\text { Node } 1>
$$

\section{Правило 2}

$<$ Node $1>::=<$ AccessMode $1><$ LPar $><$ TokenType $><$ Coma $>$

$<$ Number $><$ RPar $><$ Name $><$ Initial $>$

Правила 7 та 8

$<$ Node1 $>::=<$ AccessMode $1><$ TokenType $><$ Coma $><$ Number $>>$

$<$ Name $><$ Initial $>$

Правило 4

$<$ Node1 $>::=$ lifo $<<$ TokenType $><$ Coma $><$ Number $>>$

$<$ Name $><$ Initial $>$

Правило 6

$<$ Node1 $>::=$ lifo $<$ int $<$ Coma $><$ Number $>><$ Name $><$ Initial $>$ Правило 9

$<$ Node $1>::=$ lifo $<$ int,$<$ Number $>><$ Name $><$ Initial $>$

Правило 10

$$
<\text { Node } 1>::=\text { lifo }<\text { int },<\text { Number }>>\mathrm{n} 1<\text { Initial }>
$$

Правило 11

$$
<\text { Node } 1>::=\text { lifo }<\operatorname{int~}, 5>\mathrm{n} 1<\text { Initial }>
$$

Правило 13

$<$ Node1 $>::=$ lifo $<$ int, $5>\mathrm{n} 1<$ LPar $><$ LPar $>1<$ Initial $>$

Правило 7

$$
<\text { Node } 1>::=\text { lifo }<\text { int }, 5>\mathrm{n} 1<<1<\text { Initial }>
$$

Правило 13

$<$ Node $1>::=$ lifo $<$ int, $5>\mathrm{n} 1<<1<$ LPar $><$ LPar $>2<$ Initial $>$

Правило 7

$$
<\text { Node1 }>::=\text { lifo }<\text { int }, 5>\mathrm{n} 1<<1<<2<\text { Initial }>
$$

Правило 13

$<$ Node1 $>::=$ lifo $<$ int, $5>\mathrm{n} 1<<1<<2<$ LPar $>$

$$
<\text { LPar }>3<\text { Initial }>
$$

\section{Правило 7}

$<$ Node1 $>::=$ lifo $<$ int, $5>\mathrm{n} 1<<1<<2<<3<$ Initial $>$ Правило 13

$<$ Node1 $>::=$ lifo $<$ int, $5>\mathrm{n} 1<<1<<2<<3<$ End $>$

Правило 14

$$
<\text { Node1 }>::=\text { lifo }<\text { int }, 5>\mathrm{n} 1<<1<<2<<3,
$$




\section{Висновки}

Запропоновані контекстно-вільно граматика та формальні моделі дають змогу автоматизувати синтез програмного коду вузла мережі Петрі. Побудова множини правил граматики здійснена у відповідності до синтаксису мови POSES++, тому покрокове застосування правил дозволяе отримати синтаксично та семантично вірний код мовою POSES++.

\section{Література}

1. Томашевский В.Н., Купрашвили А.Ю., Савустьяненко Э.И. Организация интерактивной системы моделирования // Электронное моделирование. - 1987. - 1. - С. 16-19.

2. Богушевська Н.В., Звіряка Є.Д. Взаємодія CASE-пакету ISS2005 із системою імітаційного моделювання //III Всеукраїнська наук.-техн. конф. молодих учених та студентів "Інформаційні технології в економічних та технічних системах -2009”, м.Кременчук - 2009. - С.145 -147 .

3. Complete Overview of Petri Nets Tools Database / Режим доступу http://www.inf ormatik.uni-hamburg.de/TGI/PetriNets/tools

4. Баляница Н.А., Богушевская Н.В. Определение формальных моделей основных моделируемых конструкций языка POSES ++ для расширения возможностей системы ISS 2000// Міжн. наук. конф. "Інтелектуальні системи прийняття рішень та прикладні аспекти інформаційних технологій”, м. Свпаторія. - 2009. - т.1. с.12-15.

5. Баляница Н.А., Богушевская Н.В. Определение правил создания типов данных языка POSES++ для использования в системе ISS 2000// Четверта науково-практична конференція з міжнародною участю “Математичне та імітаційне моделювання систем МОДС '2009”, м. Київ. С.184-188.

Отримано 11.03.2011 p. 